\title{
EFEITOS DA TEMPERATURA SOBRE A ATIVIDADE DE FUNGOS NO CONTROLE BIOLÓGICO DE Meloidogyne javanica E M. incognita RAÇA 3
}

\author{
FÁBIO R. ALVES ${ }^{1}$ \\ VICENTE PAULO CAMPOS ${ }^{2}$
}

\begin{abstract}
RESUMO - O efeito de Arthrobotrys conoides, Duddingtonia flagrans, Paecilomyces lilacinus, Paecilomyces variotii, Monacrosporium doedycoides e um isolado de rizobactéria na reprodução e crescimento populacional de Meloidogyne javanica e M. incognita raça 3 em tomateiro Santa Clara, suscetível à Meloidogyne spp., foi estudado em três ambientes distintos: 1) casa-devegetação sem controle de temperatura; 2) sala climatizada com temperatura do ar constante a $24^{\circ} \mathrm{C}$; 3) em banho-maria com temperatura do solo mantida em 29 $30^{\circ} \mathrm{C}$, colocado na mesma sala climatizada caracterizada anteriormente. Maior crescimento populacional de $M$. javanica e de $M$. incognita raça 3 ocorreu em solo aquecido, comparado com aquela em casa-de-
\end{abstract}

vegetação e sala climatizada, e o número de galhas causado por $M$. javanica e $M$. incognita raça 3 foi maior em solo aquecido e em sala climatizada do que em casa-de-vegetação. Em solo aquecido e em sala climatizada, A. conoides e a rizobactéria reduziram $(\mathrm{P} \leq 0,05)$ o número de galhas de $M$. incognita raça 3 , comparado com a testemunha. Em solo aquecido, $A$. conoides reduziu o número de ovos de $M$. incognita raça 3, comparado com a testemunha. Em casa-devegetação, todos os antagonistas reduziram o número de ovos de $M$. incognita raça 3, comparado com a testemunha. Em casa-de-vegetação, todos os antagonistas reduziram o número de ovos em relação à testemunha.

\section{EFFECT OF SOIL WARMING ON THE BIOLOGICAL CONTROL OF Meloidogyne javanica AND M. incognita RACE 3}

\begin{abstract}
The effects of Arthrobotrys conoides, Duddingtonia flagrans, Paecilomyces lilacinus, Paecilomyces variotii, Monacrosporium doedycoides and an isolate of rhizobacterium on reproductivity of Meloidogyne javanica and M. incognita race 3 on Santa Clara tomato plants, susceptible to Meloidogyne spp., were studied in three different environments: 1) greenhouse without temperature control; 2) room with air temperature controlled at $24^{\circ} \mathrm{C} ; 3$ ) watherbath with soil temperature controlled at $29-30^{\circ} \mathrm{C}$, placed in the room with the temperature controlled at $24^{\circ} \mathrm{C}$. Greatest M. javanica and $M$. incognita race 3 reproductivity
\end{abstract}

occurred in waterbath warmed soil than in greenhouse and temperature controlled room. Galls number caused by $M$. javanica and $M$. incognita race 3 was greater in waterbath warmed soil and temperature controlled room than in greenhouse. In waterbath warmed soil and in temperature controlled room, A. conoides and rhizobacterium reduced $(\mathrm{P} \leq 0,05)$ the galls number of M. incognita race 3 compared to control. A. conoides also reduced the eggs number of $M$. incognita race 3 compared to control in waterbath warmed soil. In greenhouse, all antagonistics used reduced the eggs number compared to control.

INDEX TERMS: Biological control, Meloidogyne, temperature.

1. Engenheiro Agrônomo, MSc., UFLA/DFP, Caixa Postal 37, 37.200-000, Lavras, MG

2. Engenheiro Agrônomo, Dr., Professor Titular, UFLA/DFP, Caixa Postal 37, 37.200-000, Lavras, MG. 


\section{INTRODUÇÃO}

A temperatura é fator abiótico que afeta plantas e populações de microrganismos no solo. As temperaturas ótimas para a eclosão de juvenis de segundo estádio (J2) de $M$. incognita e $M$. javanica variam de 25 a $30^{\circ} \mathrm{C}$ (Tihohod, 1993). A taxa de embriogênese em $M$. javanica em temperatura de $15^{\circ} \mathrm{C}$ foi aproximadamente 4 a 5 vezes menor do que aquela a $30^{\circ} \mathrm{C}$ (Bird, 1972). Maior taxa de penetração de $\mathrm{J} 2$ de $M$. javanica, $M$. incognita e $M$. arenaria em plantas de soja ocorreram em temperatura média de $21^{\circ} \mathrm{C}$ (Herman et al., 1991; Gourd et al., 1993; Pedrosa et al. 1996). Porém, quando a temperatura do solo é superior a $28^{\circ} \mathrm{C}$, a resistência do tomateiro com o gene Mi é reduzida (Dropkin, 1969; Ammati et al., 1986). Mesmo em plantas suscetíveis, o crescimento populacional de Meloidogyne spp. é sempre maior quando a temperatura do solo é maior que $28^{\circ} \mathrm{C}$ (Ammati et al, 1986). De fato, de nove genótipos de tomateiro testados, sete apresentaram significativo aumento no número de galhas causadas por $M$. incognita raça 4 , quando cultivados em solo aquecido a $32,5^{\circ} \mathrm{C}$. Além do tomateiro (Lycopersicon esculentum Mill.), estudos demonstram, que outras culturas podem ter suas resistências diminuídas quando cultivadas em solo com temperaturas superiores a $28^{\circ} \mathrm{C}$, como o feijoeiro (Phaseolus vulgaris L.), alfafa (Mendicago sativa L.), batata-doce [Ipomoea batatas (L.) Lam] e pêssego [Prunus pérsica (L.) Batsch].

Os fungos de solo também são afetados pela elevação de temperatura. Desse modo, alguns autores já observaram que o parasitismo de alguns fungos sobre populações de Meloidogyne spp. é maior em temperaturas variando de 23 a $25^{\circ} \mathrm{C}$ do que 18 a $32^{\circ} \mathrm{C}$ (Al-Hazmi et al., 1982).

Fungos e bactérias antagonistas de nematóides têm reduzido a população de Meloidogyne spp. em condições de casa-de-vegetação (Naves \& Campos, 1991). Realmente, Coimbra (1998) obteve 130 isolados bacterianos de várias culturas e avaliou a eficiência dessas rizobactérias para controle de $M$. javanica, dos quais 40,76 \% foram eficientes antagonistas ao nematóide em uma primeira avaliação. Entretanto, ainda não se conhece o comportamento desses organismos em temperaturas altas do solo. Dessa forma, objetivou-se neste trabalho estudar o efeito de temperaturas altas na eficácia do antagonismo de fungos e de rizobactéria sobre $M$. javanica e $M$. incognita raça 3 em tomateiro.

\section{MATERIAL E MÉTODOS}

Os fungos antagonistas Paecilomyces lilacinus (Thom) Sanson, Paecilomyces variotii Barn, Monacrosporium doedycoides (Drechsler) Cooke \& Dickinson, Arthrobotrys conoides Drechsler foram isolados do solo e de massas de ovos de Meloidogyne spp. O fungo Duddingtonia flagrans foi fornecido pelo Laboratório de Parasitologia do Departamento de Medicina Veterinária da UFLA, Lavras-MG.

As culturas dos fungos foram repicadas em câmara de fluxo laminar para placas de Petri contendo meia batata-dextrose-ágar (BDA), as quais foram incubadas em câmara de crescimento (BOD) a $25^{\circ} \mathrm{C}$. Quinze dias após, discos de $5 \mathrm{~mm}$ de diâmetro foram retirados das bordas das colônias fúngicas e repicados para frascos de vidro de $500 \mathrm{ml}$ contendo $100 \mathrm{~g}$ de grãos de trigo pré-cozidos por um período de 10 minutos, e esterilizados em autoclave a $120^{\circ} \mathrm{C}$ por 1 hora/dia durante três dias consecutivos. A seguir, os frascos foram mantidos a $24^{\circ} \mathrm{C}$ por vinte e um dias.

Dez gramas de grãos de trigo colonizados foram triturados em liquidificador por 30 segundos. Determinaram-se o número total de esporos com auxílio de câmara de neubauer e o peso das hifas + esporos fúngicos em $10 \mathrm{~g}$ de trigo colonizado. O número de esporos foi de $2,13 \times 10^{11}, 7,61 \times 10^{10}, 1,34 \times 10^{8}, 1,88 \times 10^{7} \mathrm{e}$ $2,90 \times 10^{7}$ para P. lilacinus, P. variotii, M. doedycoides, A. conoides e D. flagrans, respectivamente, e os pesos das hifas e esporos foram 0,$98 ; 1,75 ; 0,24$; 1,30 e 1,80 g para os respectivos fungos. Utilizaramse $10 \mathrm{~g}$ do trigo colonizado por litro de substrato como inóculo fúngico na condução dos ensaios experimentais.

Foi utilizado o isolado rizobacteriano n... 136 de tomateiro obtido por Coimbra (1998), o qual estava preservado em "deep freezer" a $-80^{\circ} \mathrm{C}$. Após o descongelamento, esse isolado foi repicado, com auxílio de uma alça de cromo níquel, para placas de Petri contendo o meio "trypic soy Agar" (TSA), que foram incubadas a $25^{\circ} \mathrm{C}$ em BOD. Após $48 \mathrm{~h}$, foram preparadas suspensões adicionando-se às placas solução de sulfato de magnésio $\left(\mathrm{MgSO}_{4}\right)$ 0,1M e desprendendo-se as colônias bacterianas com auxílio de uma alça de Drigalski. A concentração dessa suspensão foi ajustada em espectrofotômetro para $\mathrm{A}_{550}=1,0$, aproximadamente $10^{9}$ células bacterianas por $\mathrm{mL}$.

Meloidogyne javanica e $M$. incognita raça 3 foram multiplicadas e mantidas em raízes de tomateiro (Lycopersicon esculentum Mill.) cultivar Santa Clara, em casa-de-vegetação. Após 70 dias da inoculação das plantas, realizaram-se a extração e a contagem de ovos

Ciênc. agrotec., Lavras. V.27, n.1, p.91-97, jan./fev., 2003 
do sistema radicular do tomateiro, empregando-se uma técnica modificada por Bonetti \& Ferraz (1981). Em seguida, fez-se a contagem de ovos para quantificação do inóculo inicial a ser usado no experimento.

O substrato formado de areia, solo e esterco na proporção de 2:1:1, esterilizado, foi infestado com os fungos antagonistas, homogeneizando-se $10 \mathrm{~g}$ do trigo colonizado por recipiente. Logo após a infestação do solo com os fungos antagonistas, mudas de tomateiro cultivar Santa Clara foram transplantadas para os vasos, onde permaneceram até a inoculação de $M$. javanica ou $M$. incognita raça 3 com 15.000 ovos de $M$. javanica ou de M. incognita raça 3, que acorreu 14 dias mais tarde.

A inoculação das plantas com a rizobactéria foi feita pela bacterização das raízes antes do transplantio, distribuindo as mudas dentro de um béquer contendo a suspensão bacteriana, onde foram imersas por $10 \mathrm{minu}-$ tos, e a seguir transplantadas para vasos onde permaneceram por 10 dias, até que fosse feita a inoculação com M. javanica ou M. incognita raça 3.

Para cada antagonista testado, foram feitas 15 repetições, sendo colocadas cinco delas em cada um dos três ambientes diferentes com relação à temperatura do solo. O ambiente 1 foi caracterizado como solo aquecido. Um aquecedor tipo banho-maria foi construído especialmente para aquecer solo a $29-31^{\circ} \mathrm{C}$ no interior de recipientes de aço inoxidável de $1,2 \mathrm{~kg}$ (Figura 1), o qual foi colocado numa sala climatizada $\left(24-26^{\circ} \mathrm{C}\right)$. Desse modo, no ambiente 1 , o solo era mantido a 29 $31^{\circ} \mathrm{C}$, a temperatura do ar a $24-26^{\circ} \mathrm{C}$ e a iluminação dentro do espectro visível $(380-780 \mathrm{~nm})$. O ambiente 2 constou de solo não aquecido, porém as plantas foram mantidas na mesma sala climatizada com temperatura do ar de $24-26^{\circ} \mathrm{C}$ e iluminadas da mesma forma do ambiente 1 . $\mathrm{O}$ ambiente 3 foi o de casa-de-vegetação, sem controle de temperatura do ar e do solo, com os recipientes de aço inoxidável acondicionados em vasos plásticos de $4 \mathrm{~L}$ de capacidade envoltos em areia umedecida para evitar o aquecimento excessivo do solo. Nos três ambientes, foram colocados sensores imersos no substrato contido nos recipientes onde estavam as plantas, para medir a umidade e temperatura do solo. Sensores também foram colocados suspensos a aproximadamente 1,5 $\mathrm{m}$ acima dos recipientes, para registrar a umidade e temperatura do ar. Esses sensores foram conectados a cabos ligados a 'datallogers', os quais registravam todos os dados a cada 60 minutos. Os dados dos 'datallogers' foram

descarregados em computador por meio do programa Pclink 4.0, desenvolvido exclusivamente para esse fim.
O delineamento estatístico foi distribuição inteiramente casualizada com dois fatores. O fator 1 constituiu-se de sete tratamentos, que foram: P. lilacinus, $P$. variotii, $M$. doedycoides, $A$. conoides, $D$. flagrans, a rizobactéria e testemunha (plantas de tomate inoculadas com nematóides mas não tratadas com antagonista). O fator 2 constituiu-se dos ambientes, solo aquecido, casade-vegetação e sala climatizada.

Para análise estatística, utilizou-se o programa SAEG e os dados foram transformados em $\sqrt{\mathrm{x}+1}$.

Vinte e oito dias após a inoculação das plantas com os nematóides, cortou-se a parte aérea das plantas, lavou-se o sistema radicular e contaram-se as galhas de todo o sistema radicular livre de detritos. Em seguida, o sistema radicular foi pesado para obtenção do peso fresco das raízes por planta, e calculou-se, para efeito de padronização, o número de galhas por $5 \mathrm{~g}$ de raízes. Todo o sistema radicular de cada planta, livre de solo e detritos orgânicos, foi cortado em pedaços de $0,5 \mathrm{~cm}$ e cada porção de 50 a 100 gramas de raízes foi colocada por vez em liquidificador com $200 \mathrm{~mL}$ de hipoclorito de sódio a $0,5 \%$ e trituradas durante 1 minuto, segundo o método modificado por Bonetti \& Ferraz (1981). Dessa suspensão, foram obtidas três alíquotas de $1 \mathrm{~mL}$ cada uma e contados os ovos em microscópio de objetiva invertida, obtendo-se a média. $\mathrm{O}$ número de ovos/ml da suspensão foi multiplicado pelo volume total da suspensão e obtido o número de ovos por sistema radicular (população final).

\section{Determinação do acúmulo de graus-dias du- rante os experimentos}

O cálculo dos graus-dias foi feito utilizando-se a expressão citada por Silveira Neto et al. (1976). Tal expressão foi primeiramente utilizada em trabalhos nematológicos por Tyler (1933), que estimou o limiar de desenvolvimento para Meloidogyne spp. em $10{ }^{\circ} \mathrm{C}$. A equação $\mathrm{K}=\mathrm{y}(\mathrm{t}-\mathrm{Tb})$, em que $\mathrm{K}=$ constante térmica expressa em graus-dias; $\mathrm{y}=$ número de dias para o ciclo total; $\mathrm{t}=$ temperatura (câmara de crescimento ou campo); $\mathrm{Tb}=$ temperatura base $\left(10^{\circ} \mathrm{C}\right)$, foi empregada nos cálculos.

Assim, com os dados de temperatura e utilizando a equação acima, calculou-se a demanda de energia térmica em graus-dias durante o período experimental.

$\mathrm{O}$ acúmulo de graus-dias em cada ambiente, isto é, casa-de-vegetação, sala climatizada sem aquecimento do solo e com o solo aquecido foi de 8.400,0, 9.273,6 e $12.969,0$, respectivamente. 


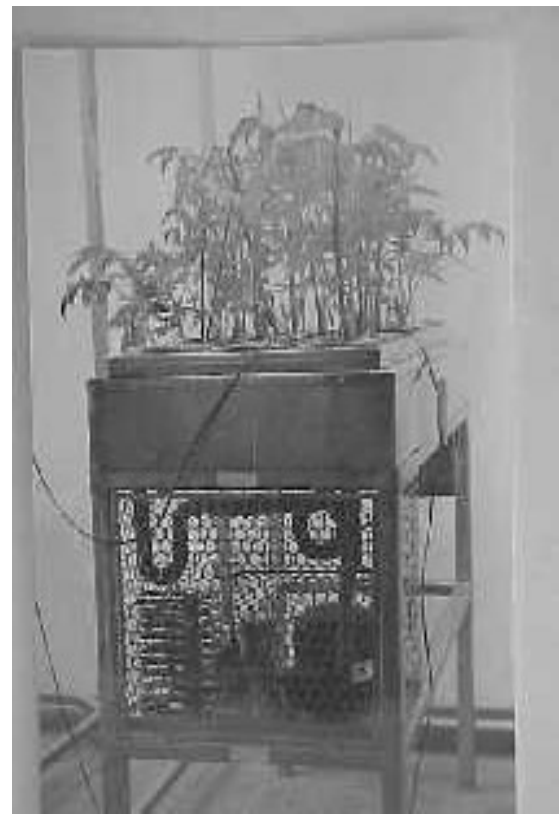

FIGURA 1 - Banho-maria para aquecimento do solo em 24 recipientes de aço inoxidável de 1,2 Kg de capacidade.

\section{RESULTADOS E DISCUSSÃO}

O aquecimento do solo a $29,3^{\circ} \mathrm{C}$ induziu a um aumento significativo na reprodução de $M$. javanica e M. incognita raça 3, comparado com aquela em casa-devegetação e sala climatizada (Tabela 1), em razão, talvez, da maior penetração de juvenis do segundo estádio (J2) nas raízes das plantas, como constatado por Kaur \& Mahajan (1992), trabalhando com genótipos de tomateiro inoculados com $M$. incognita em diversas temperaturas. Entretanto, a formação de galhas foi semelhante entre as plantas mantidas em solo aquecido e na sala climatizada, e diferente $(\mathrm{P} \leq 0,05)$ daquela em casa-devegetação (Tabela 1), demonstrando que o pequeno acréscimo na temperatura do solo na sala climatizada aumentou significativamente a formação de galhas, mas não a reprodução. Ammati et al. (1986) verificaram que os nematóides formadores de galhas são muito ativos em temperaturas altas do solo, podendo penetrar eficientemente nas raízes das plantas, mesmo na presença de fungos antagonistas.

$\mathrm{O}$ número de galhas produzido por $M$. incognita raça 3 foi significativamente reduzido pelas inoculações de Arthrobotrys conoides e rizobactéria, comparado com a testemunha (Tabela 2). Esses dados estão de acordo com aqueles encontrados por Al-Hazmi et al. (1982), que em testes em casa-de-vegetação observaram uma redução de 67-84 \% do número de galhas causadas por $M$. incognita em raízes de milho em vasos tratados com A. conoides, quando comparado com aqueles tratamentos que não receberam o fungo.

$\mathrm{O}$ número de galhas produzido por $M$. javanica nos três ambientes testados foi igual somente quando se inoculou A. conoides (Tabela 3). Quando se utilizou esse mesmo fungo observou-se igual número de galhas e de ovos produzidos por $M$. incognita raça 3 nos três ambientes. Como esse fungo se mostrou eficiente no biocontrole de Meloidogyne incognita nos três ambientes, A. conoides pode ser uma boa opção para controle biológico de Meloidogyne spp. em regiões onde temperaturas médias são elevadas, como é o caso do Nordeste, onde Meloidogyne incognita é altamente difundido e causa consideráveis prejuízos a várias culturas. Todavia, estudos em condições de campo são necessários. Embora não haja relatos sobre o efeito de temperatura na atividade de A. conoides sobre Meloidogyne spp., Den Belder \& Jansen (1994) demonstraram que o melhor intervalo de temperatura para crescimento micelial de $A$. conoides foi de 23 a $28^{\circ} \mathrm{C}$. Já em outro estudo realizado em casa-de-vegetação, Al-Hazmi et al. (1982) observaram uma redução de $67-84 \%$ do número de galhas causadas por M.incognita em raízes de milho em vasos tratados com $A$. conoides, quando comparado com aqueles tratamentos que não receberam o fungo.

Ciênc. agrotec., Lavras. V.27, n.1, p.91-97, jan./fev., 2003 
Paecilomyces lilacinus reduziu significativamente o número de ovos de $M$. incognita raça 3 em casa-devegetação, quando comparado aos demais ambientes. Além disso, o número de galhas causadas por $M$. javanica e $M$. incognita raça 3 foi menor em casa-devegetação e sala climatizada em relação ao ambiente com solo aquecido (Tabela 3 ), o que pode ser explicado pelo fato de a temperatura de solo entre 29 e $31^{\circ} \mathrm{C}$ ser mais propicia à rápida eclosão de $\mathrm{J} 2$ (Kaur \& Mahajan, 1992), não permitindo que o fungo tivesse tempo para parasitar os nematóides.

A rizobactéria reduziu $(\mathrm{P} \leq 0,05)$ o número de galhas de $M$. incognita raça 3 nas plantas crescidas em solo aquecido e em sala climatizada e número de ovos em casa-de-vegetação (Tabela 3). Embora pouca ênfase tenha sido dada ao controle de fitonematóides por rizobactérias, muitos autores relatam a eficiência de alguns gêneros dessas bactérias para o biocontrole desses patógenos (Kloepper et al., 1991; Racke \& Sikora, 1992; Westcott \& Kluepfel, 1993). De fato, Coimbra (1998), numa primeira seleção de 130 isolados rizobacterianos, obteve $40,76 \%$ deles com efeito antagonista a $M$. javanica. Já, Naves (2000) avaliou o potencial de 40 isolados de bactérias endofíticas no controle de $M$. javanica e observou que todos os isolados reduziram o número de galhas em 18,97-56,68 \%. Com exceção de apenas três isolados, os demais reduziram em 20,75-64,87\% o número de ovos em testes em casa-de-vegetação.

Em casa-de-vegetação todos os antagonistas testados reduziram o número de ovos de $M$. incognita raça 3, comparado com a testemunha, demonstrando maior efeito quando a população do nematóide é mais baixa. Realmente, no campo, onde há condições extremamente favoráveis à reprodução de Meloidogyne spp., como solo arenoso, umidade adequada e temperaturas elevadas, condições essas observadas no ambiente com solo aquecido durante o período experimental, a população do nematóide atinge níveis tão altos, que medidas de controle, ainda que integradas, são, muitas vezes, pouco eficientes.

TABELA 1 - Efeito dos ambientes de crescimento dos tomateiros no número de galhas e de ovos produzidos por Meloidogyne javanica $(\mathrm{Mj})$ e Meloidogyne incognita raça 3 (Mi).

\begin{tabular}{lccccc}
\hline & $\begin{array}{c}\text { Temperatura do } \\
\text { solo }\left({ }^{\circ} \mathbf{C}\right) *\end{array}$ & \multicolumn{2}{c}{$\mathbf{N}^{\mathbf{0}} \ldots$ de galhas $/ \mathbf{5}$ g de raiz } & \multicolumn{2}{c}{$\mathbf{N}^{\mathbf{0}} \ldots$ total de ovos } \\
\cline { 3 - 6 } Ambientes & & $\mathrm{Mj}$ & $\mathrm{Mi}$ & $\mathrm{Mj}$ & $\mathrm{Mi}$ \\
\hline Solo aquecido & 29,3 & $579,7 \mathrm{~b}$ & $468,1 \mathrm{~b}$ & $33027,7 \mathrm{~b}$ & $30914,1 \mathrm{~b}$ \\
\hline Casa-de-vegetação & 22,5 & $75,6 \mathrm{a}$ & $51,1 \mathrm{a}$ & $161,7 \mathrm{a}$ & $140,0 \mathrm{a}$ \\
\hline Sala climatizada & 23,8 & $589,6 \mathrm{~b}$ & $401,4 \mathrm{~b}$ & $198,8 \mathrm{a}$ & $212,5 \mathrm{a}$ \\
\hline
\end{tabular}

Média dos dados registrados a cada hora em "datallogers" durante o período experimental

Médias seguidas de letras diferentes nas colunas diferem entre si a $5 \%$ de probabilidade pelo teste de Tukey

TABELA 2 - Efeito dos diversos organismos antagonistas de nematóides testados no número galhas e de ovos produzidos por Meloidogyne javanica (Mj) e Meloidogyne incognita raça 3 (Mi).

\begin{tabular}{lcccc}
\hline & \multicolumn{2}{c}{$\mathbf{N}^{\mathbf{0}}$.. de galhas/5 g de raiz } & \multicolumn{2}{c}{$\mathbf{N}^{\mathbf{0}} \ldots$ total de ovos } \\
\cline { 2 - 5 } Antagonistas & $\mathrm{Mj}$ & $\mathrm{Mi}$ & $\mathrm{Mj}$ & $\mathrm{Mi}$ \\
\hline Paecilomyces lilacinus & $829,9 \mathrm{~b}$ & $484,5 \mathrm{ab}$ & $17924,1 \mathrm{a}$ & $14221,0 \mathrm{a}$ \\
\hline Paecilomyces variotii & $466,6 \mathrm{ab}$ & $196,0 \mathrm{ab}$ & $11268,6 \mathrm{a}$ & $12572,8 \mathrm{a}$ \\
\hline Monacrosporium doedycoides & $497,7 \mathrm{ab}$ & $457,0 \mathrm{ab}$ & $3701,1 \mathrm{a}$ & $9081,7 \mathrm{a}$ \\
\hline Arthrobotrys conoides & $201,5 \mathrm{a}$ & $114,0 \mathrm{a}$ & $10297,5 \mathrm{a}$ & $2692,4 \mathrm{a}$ \\
\hline Duddingtonia flagrans & $314,0 \mathrm{a}$ & $243,4 \mathrm{ab}$ & $10297,5 \mathrm{a}$ & $13155,7 \mathrm{a}$ \\
\hline Rizobactéria & $285,2 \mathrm{a}$ & $115,3 \mathrm{a}$ & $5264,4 \mathrm{a}$ & $10195,9 \mathrm{a}$ \\
\hline Testemunha & $354,8 \mathrm{a}$ & $602,5 \mathrm{~b}$ & $10583,5 \mathrm{a}$ & $12508,2 \mathrm{a}$ \\
\hline
\end{tabular}

Médias seguidas de letras diferentes nas colunas diferem entre si a $5 \%$ de probabilidade pelo teste de Tukey 
TABELA 3 - Efeito dos antagonistas de nematóides testados em três ambientes diferentes: solo aquecido em sala climatizada, casa-de-vegetação e sala climatizada, no número galhas e de ovos produzidos por Meloidogyne javanica e Meloidogyne incognita raça 3.

\begin{tabular}{|c|c|c|c|c|c|c|}
\hline \multirow{2}{*}{$\begin{array}{l}\text { Meloidogyne javanica } \\
\text { Organismos antagonistas }\end{array}$} & \multicolumn{3}{|c|}{$\mathrm{N}^{\circ} \ldots$ de galhas $/ 5 \mathrm{~g}$ de raiz } & \multicolumn{3}{|c|}{$N^{o} \ldots$ total de ovos } \\
\hline & $\begin{array}{c}\text { Solo } \\
\text { aquecido }\end{array}$ & $\begin{array}{c}\text { Casa-de- } \\
\text { vegetação }\end{array}$ & $\begin{array}{c}\text { Sala } \\
\text { climatizada }\end{array}$ & $\begin{array}{c}\text { Solo } \\
\text { aquecido }\end{array}$ & $\begin{array}{c}\text { Casa-de- } \\
\text { vegetação }\end{array}$ & $\begin{array}{c}\text { Sala } \\
\text { climatizada }\end{array}$ \\
\hline Paecilomyces lilacinus & 1156,3 b B & 56,0 a $\mathrm{A}$ & 906,3 b B & 41435,0 a B & 114,0 a $\mathrm{A}$ & 350,0 a $\mathrm{A}$ \\
\hline Paecilomyces variotii & $1070,0 \mathrm{ab} B$ & 56,0 a A & $274,0 \mathrm{ab} \mathrm{AB}$ & 33644,6 a B & 131,0 a A & 30,3 a A \\
\hline Monacrosporium doedycoides & $423,0 \mathrm{ab} \mathrm{AB}$ & 75,3 a $\mathrm{A}$ & 945,0 b B & 25344,0 a B & 127,3 a A & 60,6 a A \\
\hline Arthrobotrys conoides & $346,0 \mathrm{ab} \mathrm{A}$ & 108,7 a $\mathrm{A}$ & 150,0 a A & 30621,7 a B & 163,2 a A & 107,5 a A \\
\hline Duddingtonia flagrans & 184,7 a A & 73,5 a A & $683,7 \mathrm{ab} B$ & 15569,7 a B & 157,0 a A & 66,5 a $\mathrm{A}$ \\
\hline Rizobactéria & $662,5 \mathrm{ab} B$ & 22,5 a A & 662,3 ab B & 54388,5 a B & 106,0 a $\mathrm{A}$ & 752,0 a A \\
\hline Testemunha & $646,5 \mathrm{ab} B$ & 132,2 a A & $621,3 \mathrm{ab} B$ & 41471,0 a B & 321,3 a $A$ & 99,3 a $\mathrm{A}$ \\
\hline
\end{tabular}

\begin{tabular}{|c|c|c|c|c|c|c|}
\hline \multirow{2}{*}{$\begin{array}{c}\text { Meloidogyne incognita raça } 3 \\
\text { Organismos antagonistas }\end{array}$} & \multicolumn{3}{|c|}{$\mathrm{N}^{\circ} \ldots$ de galhas $/ 5 \mathrm{~g}$ de raiz } & \multicolumn{3}{|c|}{$\mathrm{N}^{\circ} \ldots$ total de ovos } \\
\hline & $\begin{array}{c}\text { Solo } \\
\text { aquecido }\end{array}$ & $\begin{array}{c}\text { Casa-de- } \\
\text { vegetação }\end{array}$ & $\begin{array}{c}\text { Sala } \\
\text { climatizada }\end{array}$ & $\begin{array}{c}\text { Solo } \\
\text { aquecido }\end{array}$ & $\begin{array}{c}\text { Casa-de- } \\
\text { vegetação }\end{array}$ & $\begin{array}{c}\text { Sala } \\
\text { climatizada }\end{array}$ \\
\hline Paecilomyces lilacinus & $979,5 \mathrm{ab} B$ & 75,0 a $\mathrm{A}$ & $370,6 \mathrm{ab} \mathrm{AB}$ & 39015,0 b B & 86,5 a $A$ & $8,6 \mathrm{ab} A$ \\
\hline Paecilomyces variotii & 287,0 bc B & 17,3 a $\mathrm{A}$ & $550,0 \mathrm{ab} B$ & 37410,0 b B & 145,6 a A & $180,0 \mathrm{ab} \mathrm{A}$ \\
\hline Monacrosporium doedycoides & $578,3 \mathrm{abc} A B$ & 117,7 a A & $788,0 \mathrm{ab} B$ & $29986,0 \mathrm{ab} B$ & 158,5 a A & $75,0 \mathrm{ab} A$ \\
\hline Arthrobotrys conoides & 65,2 a $\mathrm{A}$ & 22,0 a A & 254,7 a A & 7949,5 a A & 114,2 a A & 13,5 a A \\
\hline Duddingtonia flagrans & 251,0 a $\mathrm{AB}$ & 61,6 a $\mathrm{A}$ & $372,2 \mathrm{ab} B$ & $36041,0 \mathrm{ab} B$ & 27,0 a $\mathrm{A}$ & $117,0 \mathrm{ab} \mathrm{A}$ \\
\hline Rizobactéria & 173,2 a A & 14,7 a $\mathrm{A}$ & 158,2 a $\mathrm{A}$ & $29640,0 \mathrm{ab} B$ & 108,2 a $\mathrm{A}$ & 839,5 b A \\
\hline Testemunha & 1295,0 c B & 188,0 a A & $555,3 \mathrm{~b}$ AB & 47839,0 b B & 978,6 b A & 488,6 ab A \\
\hline
\end{tabular}

Médias seguidas de letras minúsculas e maiúsculas diferentes nas colunas e linhas, respectivamente, diferem entre si ao nível de $5 \%$ de probabilidade pelo teste de Tukey.

\section{REFERÊNCIAS BIBLIOGRÁFICAS}

AL-HAZMI, A. S.; SCHIMITT, D. P.; SASSER, J. N. The effect of Arthrobotrys conoides on Meloidogyne incognita populations densities in corn as influenced by temperature, fungus inoculum density and of fungus introduction in the soil. Journal of Nematology, DeLeon Springs, v. 14, n. 2, p. 168-174, Apr. 1982.

AMMATI, M.; THOMASON, I. J.; McKINNEY, H. E Retention of resistance to Meloidogyne incognita in $L y$ - copersicon genotypes at high soil temperature. Journal of Nematology, Raleigh, v. 18, n. 4, p. 491-495, Oct. 1986.

BIRD, A. F. Influence of temperature on embryogenesis in M. javanica. Journal of Nematology, Saint. Paul, v. 4, p. 206-213, 1972.

BONNETI, J. I. S. FERRAZ, S. Modificação do método de Hussey \& Barker para extração de ovos de Meloidogyne exigua em raízes de cafeeiro. Fitopatologia Brasileira, Brasília, v. 6, n. 3, p. 553, 1981. 
COIMBRA, J. L. Rizobactérias antagonistas a Meloidogyne javanica, isolamento e parasitismo de fungos de fêmeas de Meloidogyne sp. 1998. Dissertação (Mestrado) - Universidade Federal de Lavras, Lavras.

DEN BELDER, E.; JANSEN, E. Capture of plantparasitic nematodes by an adhesive hyphae forming isolate of Arthrobotrys oligospora and some other nematode-trapping fungi. Nematologica, Leiden, v. 40, p. 423-437, July 1994.

DROPKIN, V. H. The necrotic reaction of tomatoes and other horts resistant to Meloidogyne: riversal by temperature. Phytopathology, Saint Paul, v. 59, n. 11, p. 1632-1637, Nov. 1969.

GOURD, J. R.; SCHMITT, D. P.; BARKER, K. R. Penetration rates by second-stage juveniles of Meloidogyne spp. and Heterodera glycines into soybean roots. Journal of Nematology, Lawrence, v. 25, n. 1, p. 3841, 1993.

HERMAN, M.; HUSSEY, R. S.; BOERMA, H. R. Penetration and development of $M$. incognita on roots of resistant soybean genotypes. Journal of Nematology, Lawrence, v. 23, n. 2, p. 155-161, 1991.

KAUR, D. J.; MAHAJAN, R. Effect of two temperature regimes on the expression of resistance to Meloidogyne incognita in resistant tomato cultivars. Nematologia Mediterrânea, Bari, v. 20, n. 2, p. 221-22, Dec. 1992.

KLOEPPER， J. W.; RODRIGUEZ-KABANA， R.; McINROY, J. A.; COLLINS, D. J. Analys of populations and physiological characterization of microorganisms in the rhizosphere of plant with antagonistic properties to phytopatogenic nematodes. Plant and Soil, Ulbum, v. 136, n. 1, p. 95-102, 1991.
NAVES, R. L. Bactérias endofíticas do sistema radicular: isolamento e potencial para o controle biológico de fitonematóides. 2000. 113 p. Tese (Doutorado em Nematologia) - Universidade Federal de Lavras, Lavras.

NAVES, R. L.; CAMPOS, V. P. Ocorrência de fungos predadores de nematóides no sul de Minas Gerais e estudo da capacidade predatória e crescimento "in vitro" de alguns de seus isolados. Nematologia Brasileira, Piracicaba, v. 15, n. 2, p. 152-162, fev. 1991.

PEDROSA, E. M; HUSSEY, R. S.; BOERMA, H. R. Penetration and pos-infectional development and reproduction of $M$. arenaria race 1 and 2 on susceptible and resistant soybean genotypes. Journal of Nematology, Hanover, v. 28, p. 343-351, 1996.

RACKE, J.; SIKORA, R. A. Isolation, formulation and antagonistic activity of rhizobacteria toward the potato cyst nematode Globodera pallida. Soil Biological Biochemistry, Oxford, v. 24, n. 6, p. 521-526, 1992.

SILVEIRA NETO, S. L.; NAKANO, O.; BARBIN, D.; VILLA-NOVA, N. A. Manual de ecologia dos insetos. São Paulo: Ceres, 1976. 419 p.

TIHOHOD, D. Nematologia Agrícola Aplicada. Jaboticabal: FUNEP, 1993. 372 p.

TYLER, J. Development of the root-knot nematode as affected by temperature. Hilgardia, Oakland, v. 7, n. 10, p. 391-413, Apr. 1933.

WESTCOTT, S. W.; KLUEPFEL, D. A. Inibition of Criconemella xenoplax egg hatch by Pseudomonas aureofaciens. Phytopathology, Saint Paul, v. 83, n. 11, p. 1245-1249, Nov. 1993. 